\title{
ENJOY NOW OR LATER: AN EXPLANATION OF ELDERLY RECIPIENTS' PREFERENCES REGARDING LUXURY GIFTS
}

\author{
Azadeh Kazeminia, Luleå University of Technology, Sweden \\ Lars Bäckström, Luleå University of Technology, Sweden \\ Leyland Pitt, Simon Fraser University, Canada
}

\begin{abstract}
More than 100 billion dollars are spent annually on gifts in the U.S., which makes gift-giving behaviour an important area of study. Belk (1996) describes a perfect gift as a luxury good which is exclusively relevant to the recipient. By means of selecting and transferring gifts, the giver is aiming to convey an important symbolic massage (e.g., love, admiration, appreciation, reciprocity), which needs to be perceived precisely by the receiver. Consideration for the recipient's perception of the luxury gift may address the need for the gift to be exclusively relevant to the recipient. Aging and demographic changing trends led to a growing number of elderly people who on average enjoy a higher level of wealth and are more capable of engaging in gift-exchange relationships. While the elderly as gift givers have received considerable attention, very little research has been done regarding the elderly as recipients, and many things are left to be said. Recent studies in the field of gerontology suggest that motivational changes in old age cause the elderly to give higher value to emotional well-being which might have some bearings on their behaviour. The current study will attempt to conceptually explain how the emotional state of the elderly affect the types of luxury brands they prefer to receive as gifts.

Berthon et al. (2009) argue that luxury is more than a characteristic or set of attributes and therefore should be thought of as a concept consisting of three value dimensions -the functional (the physical attributes the brand possesses), the symbolic (what the brand means to others), and the experiential (what the brand means to the individual). In an ontological classification, they distinguish two categories of luxury brands: enduring and transient. Enduring luxury brands were defined as expensive lasting possessions that bring prestige and social status to the owner. The pleasure of an enduring luxury item, either one that requires only money to be bought, such as a Gucci bag, or that which requires both money and expertise, such as an antique painting, is based on a sense of valuable enduring possession. However, transient luxury brands are a kind of experience that are not possessed, rather are consumed and bring the consumer evanescent enjoyment. This can include the superficial pleasure of having dinner in a luxury restaurant or the deep taste of the moment by tasting a rare black truffle; however, what is common in consuming such luxury brands is the sense of ephemeral pleasant experience.
\end{abstract}

According to Socio-emotional Selectivity Theory (SST), as soon as older adults perceive that the time left is limited, their goals shift from future-related goals to emotional ones such as goals related to emotional satisfaction, the feeling state, and drawing meaning from life, since these have more immediate payoffs. A focus on present-oriented goals makes them attend more to "experiences occurring in the moment" and gaining more positive feeling from life. Drawing on SST, it can be concluded that the age-related change in goals may shift the locus of luxury from symbolic and functional aspects to experiential one. Since older adults are more motivated by emotional goals and seek more emotional satisfaction by taking pleasure in each moment of their remaining life, they may place less value on the functional and symbolic aspects of the luxury brands. Instead, becoming more present oriented may lead them to prioritize the experiential aspect of luxury and assign higher value to the pleasure of experiencing a luxurious moment. Along with future-oriented goals that become less salient, gain of social prestige through possessing a luxury good becomes irrelevant. This statement might be witnessed through previous findings, which suggest that older adults are tending to give their cherished possession to their relatives. As a result, we believe it is reasonable to suggest that older people would prefer transient gifts over enduring ones. In other words, they prefer the gift that brings them a deep sense of pleasure in the moment and that improves their emotional wellbeing. As they perceive the time left to be too short to save the items to enjoy one day in the future, they may prefer to be invited for a dinner in a luxury restaurant and to have a pleasant time with their close relatives rather than receiving a Givenchy perfume or a Louis Vuitton bag. Thus, the research proposition for this study can be formulated as older adults prefer to receive a transient over an enduring gift.

References Available Upon Request. 